\title{
Energy density, energy costs and income - how are they related?
}

\author{
Wilma E Waterlander ${ }^{1, *}$, Wendy E de Haas ${ }^{1}$, Inge van Amstel ${ }^{1}$, Albertine J Schuit ${ }^{1,2}$, \\ Jos WR Twisk ${ }^{1}$, Marjolein Visser ${ }^{1}$, Jacob C Seidell ${ }^{1}$ and Ingrid HM Steenhuis ${ }^{1}$ \\ 'Department of Health Sciences and the EMGO Institute for Health and Care Research, Faculty of Earth and Life \\ Sciences, VU University Amsterdam, De Boelelaan 1085, 1081 HV Amsterdam, The Netherlands: ${ }^{2}$ National \\ Institute for Public Health and the Environment, Bilthoven, The Netherlands
}

Submitted 19 February 2009: Accepted 11 November 2009: First published online 11 January 2010

\begin{abstract}
Objective: To examine the association between energy density and energy costs in single food items and composed diets, and to explore differences in energy density and energy cost between income levels.

Design: A cross-sectional study using data from two Dutch cohort studies and recent national food prices. Food prices were retrieved from two market leader supermarkets. Data on dietary intake were measured using a computerized faceto-face interview (cohort 1 ) and $24 \mathrm{~h}$ recalls (cohort 2).

Setting: The Netherlands.

Subjects: A sample of 373 young adults from the Amsterdam Growth and Health Longitudinal Study (AGHLS, measured in 2000) and a sample of 200 communitydwelling elderly from the Longitudinal Ageing Study Amsterdam (LASA, measured in 2007).

Results: We found significant inverse associations between energy density and energy costs in single food items $(r=-0.436, P<0 \cdot 01)$ and composed diets (AGHLS men $r=-0.505$, women $r=-0 \cdot 413, P<0 \cdot 001$; LASA men $r=-0.559$, women $r=-0.562, P<0 \cdot 001)$. Furthermore, we found that people stratified into higher energy density quartiles consumed significantly more energy per day, less fruits and vegetables, and had significantly lower diet costs. Explorative analyses on income did not reveal significant differences regarding energy density, costs, or fruit and vegetable intake.

Conclusions: In the Netherlands also, energy density was inversely related with energy costs, implying that healthier diets cost more. However, we could not find differences in energy density or costs between income levels. Future research, using precise food expenditures, is of main importance in studying the economics of obesity and in the aim of making the healthier choice easier.
\end{abstract}

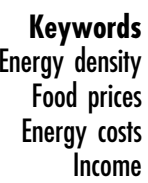

Keywords Food pices rgy costs ncome
As in many industrialized countries, the Dutch population does not have an adequate food intake according to dietary guidelines. This is true especially for people with lower socio-economic status (SES) ${ }^{(1-3)}$. Much research has focused on this topic and revealed several determinants that may explain this phenomenon. A relatively unexplored topic in this field is the economics of food choice. This is unfortunate, since price is a known important tool in marketing research ${ }^{(4,5)}$ and there are indications that food prices may be an important factor in food choice ${ }^{(6,7)}$, especially among low-income groups ${ }^{(8-10)}$. Studies in France and the USA have revealed that consuming a diet rich in energy-dense products, such as fast foods, is generally cheaper than a diet with less energy-dense products such as vegetables ${ }^{(11-13)}$. Also, a linear modelling study indicated that a cost constraint on food reduces dietary energy contributed by fruits and vegetables, and increases the share of energy-dense products, generally higher in fat and sugar ${ }^{(14)}$. These results suggest that food choice is not just a behavioural issue, but also an economic one ${ }^{(15)}$. However, the results described have only been reported in France and the USA, and it is unknown whether they also prevail in other Western countries. In order to get more insight in this, we conducted the present study with a similar methodology to the French and American studies, but this time based on Dutch data. The aim of the study was to investigate whether the described associations are also prevalent in another West European country with different dietary habits and cultural backgrounds compared with France. As it has been suggested that dietary habits in the northern regions of Europe differ from those in more 
southern ones, the northwards located Netherlands is well suited for this purpose ${ }^{(16,17)}$.

As well as studying the association between energy density and energy costs, we also conducted a first exploration into the role of income on food purchases. Previous authors have suggested that financial barriers to purchasing healthy foods may be mainly prevalent among low-income consumers, simply because a healthy diet is too expensive for these groups ${ }^{(18)}$. However, it is not clear whether low-income consumers actually consume diets with a higher energy density and whether they spend less money on food, compared with higher-income groups ${ }^{(11)}$. Therefore the second aim of our study was to gain insight into the role of income in dietary energy density and diet costs.

\section{Methods}

\section{Study population}

\section{Cobort 1}

Valuation of diet costs was based on dietary surveys conducted in two Dutch longitudinal cohort studies. The first cohort was part of the Amsterdam Growth and Health Longitudinal Study (AGHLS), consisting of a sample of Dutch adults who started in the study in 1977 at the age of 13 years. The original aim of this study was to investigate the natural development of health, fitness and lifestyle of youngsters from the general Dutch population ${ }^{(19)}$. During this study several parameters were measured repeatedly, including dietary intake. In our study we used the most recent dietary data, measured in 2000, when the subjects' mean age was 36 years ( $n$ 373). Details of the study, including examples of previously published articles, can be found in two edited books ${ }^{(20,21)}$.

\section{Cohort 2}

Since AGHLS contains data solely on a relatively healthy young adult population, analyses were also computed on an elderly population using data from the Longitudinal Ageing Study Amsterdam (LASA). This ongoing study was originally designed to investigate the changes in autonomy and well-being in the ageing population. The cohort was recruited in 1992-3 and consisted of communitydwelling elderly within the ages of 55-85 years. Sampling and data collection procedures of LASA can be found in detail elsewhere ${ }^{(22)}$. In 2007, a lifestyle study was conducted among 1421 persons meeting the following eligibility criteria: age $<80$ years, cognitively well-functioning (Mini Mental State Examination score $>23$ ) and alive on 1 January 2007. Complete lifestyle data were obtained from 1058 persons (response rate $74.5 \%$; $n 326$ no response, $n 18$ refused, $n 8$ not able due to physical problems, $n 11$ deceased). Of the 1058 persons, 516 indicated to be willing to participate in an additional nutrition sub-study of which 210 were randomly selected to be interviewed.
A complete interview was obtained from 200 persons $(95 \cdot 2 \%)$. The mean age of this sample was 69 years.

\section{Dietary assessment}

Both studies used different methods to obtain dietary intake. Fruit and vegetable intake included fresh, canned and frozen items, but excluded juices.

\section{Cobort 1}

In AGHLS, dietary intake was assessed using a computerassisted version of the face-to-face interview method (FTF), using the preceding 4 weeks as a reference period. Subjects were asked about meal types, number of meals and times of meal consumption for both average school or work days, and weekends or holidays. This provided a global idea of the respondents' consumption patterns. Subsequently a cross-check was conducted which consisted of an additional verification on the reported frequency and amounts of the consumed products. Consumption amounts were recorded in household measures or grams, for which models of glasses and spoons were used to illustrate portion sizes. The described method was validated and found to be of similar quality as the original FTF method ${ }^{(19)}$.

\section{Cobort 2}

In LASA, participants were sent a booklet with colour pictures of different food products (ranging from a buttered slice of bread to a plate with vegetables or pasta sauce) using different portion sizes. In this booklet persons were also instructed to measure the content of frequently used glasses, cups and serving spoons. The persons were telephoned unexpectedly by specifically trained dietetic students to recall their food intake of the previous $24 \mathrm{~h}$. The weight of the used food products was estimated using the portion size booklet, the measured content of commonly used kitchenware, and used recipes. Data on food intake were measured all days of the week, minimizing daily variation. For most respondents (81\%) two recalls were used, one weekday and one weekend day; for the remaining group only one recall was available.

\section{Energy density}

Analyses on energy density (defined as amount of energy per unit weight) of the consumed food items were based on energy and nutrient data of the Dutch Food Composition Database $(\mathrm{NEVO})^{(23)}$. Individual dietary energy densities (DED), defined as amount of energy per unit weight, were calculated by summing both the edible weight $(\Sigma W)$ and the energy content $(\Sigma E)$ of all foods consumed during a day and dividing those outcomes $(\mathrm{DED}=\Sigma E / \Sigma W)^{(15)}$. Based on a report by Ledikwe et al., beverages were excluded from the analyses. Generally beverages have a lower energy density than solid foods, and may therefore have a distorting effect on dietary energy density values ${ }^{(24)}$. 


\section{Estimation of diet costs}

Diet costs were estimated by linking food items from the dietary surveys with recent national food prices. National food prices $(€)$ were based on supermarket prices of two Dutch market leader supermarkets, together accounting for a $44 \%$ market share. For one supermarket, price data were obtained from a price list containing the prices of all available items in the supermarket chain, which was provided to the research team by a supermarket manager. For the other supermarket, prices were collected by use of the supermarket website (which is also available for online shopping ${ }^{(25)}$ and in-store visits. Data were collected during February to April 2008, recording mean prices and portion sizes. Based on previous methods, measures were taken on regular prices, excluding discounts. For packaged foods, the medium package size was selected; portion or bundling discounts were excluded. When multiple items of the same product were available, mean prices were calculated, including branded, house-brand and low-cost options. In a few cases consumed items were unavailable in the supermarket, such as pheasant, and had to be substituted by a comparable item, in this case turkey ${ }^{(26)}$. In the case of composed dishes, such as Chinese noodles, diet costs were calculated by summing the price of the single ingredients using standard recipes from a Dutch cookbook ${ }^{(27)}$.

After the price assignment procedure, prices per $100 \mathrm{~g}$ edible portion $(€ / 100 \mathrm{~g})$ and per $\mathrm{kJ}(€ / \mathrm{kJ})$ were calculated for each single food item. These numbers were used to calculate individual diet costs based on the following steps. First, we calculated the costs for each consumed single food item corrected for consumed amount of energy by multiplying the energy intake for each single food item (consumed kJ per food item) by the energy price of this food item $(€ / \mathrm{kJ}$ food item). Second, the consumed energy costs of all single food items were summed, resulting in diet costs for total energy intake (total $€ /$ total kJ). Finally, these total costs were corrected for total energy intake, calculating diet costs per $8368 \mathrm{~kJ}$ ( $2000 \mathrm{kcal}$; (total $€ /$ total kJ) $\times 8368)$. The described calculation method is common in this type of research and is a fair method to estimate diet costs ${ }^{(15,26,28,29)}$.

\section{Income}

In order study the effect of income we classified subjects into subgroups based on the Dutch modal income levels (Table 1). In AGHLS, data were recorded on gross annual income, measured in five levels. For analyses these groups were reassigned into three groups (below modal, modal and somewhat above modal, more than two times modal; using cut-off points before taxation). LASA used net monthly household income on the basis of eleven levels, with $€ 454-567$ as minimum and $>€ 2270$ as maximum level. Because the numbers in these groups were smaller, subjects were classified into two income groups (below modal, above modal; using cut-off points after taxation). Due to missing data, we were not able to correct for household size.

\section{Statistical analyses}

Both data sets were corrected for outliers in which participants who were outside the range of mean $\pm 2 \mathrm{SD}$ on consumed grams of fruits and vegetables and costs per $8368 \mathrm{~kJ}(2000 \mathrm{kcal})$ were excluded from analyses.

Table 1 Participant characteristics for the studied populations: young adults from the Amsterdam Growth and Health Longitudinal Study (AGHLS, measured in 2000) and community-dwelling elderly from the Longitudinal Ageing Study Amsterdam (LASA, measured in 2007)

\begin{tabular}{|c|c|c|c|c|c|c|c|c|c|}
\hline & \multicolumn{4}{|c|}{ AGHLS } & & \multicolumn{4}{|c|}{ LASA } \\
\hline & \multicolumn{2}{|c|}{ Men ( $n$ 157) } & \multicolumn{2}{|c|}{ Women (n 176) } & & \multicolumn{2}{|c|}{ Men ( $n$ 91) } & \multicolumn{2}{|c|}{ Women ( $n$ 80) } \\
\hline & Mean & SD & Mean & SD & & Mean & SD & Mean & $\mathrm{SD}$ \\
\hline Age (years) & $36 \cdot 1$ & $0 \cdot 80$ & $36 \cdot 2$ & $0 \cdot 75$ & & $68 \cdot 7$ & $3 \cdot 2$ & $68 \cdot 7$ & $3 \cdot 1$ \\
\hline Fruit $(g / d)$ & $152 \cdot 4$ & $103 \cdot 8$ & $140 \cdot 3$ & $97 \cdot 2$ & & $142 \cdot 9$ & $103 \cdot 1$ & $107 \cdot 5$ & $93 \cdot 1$ \\
\hline \multirow[t]{2}{*}{ Vegetables (g/d) } & $189 \cdot 2$ & $76 \cdot 8$ & $190 \cdot 7$ & $72 \cdot 1$ & & $136 \cdot 7$ & $79 \cdot 9$ & $142 \cdot 9$ & $87 \cdot 4$ \\
\hline & $n$ & $\%$ & $n$ & $\%$ & & $n$ & $\%$ & $n$ & $\%$ \\
\hline \multicolumn{10}{|l|}{ BMI $\left(\mathrm{kg} / \mathrm{m}^{2}\right) \dagger$} \\
\hline$<20$ & 19 & $12 \cdot 2$ & 102 & $58 \cdot 6$ & & 1 & $1 \cdot 2$ & 1 & $1 \cdot 3$ \\
\hline $20-25$ & 103 & $66 \cdot 0$ & 61 & $35 \cdot 1$ & & 23 & $26 \cdot 7$ & 17 & $21 \cdot 5$ \\
\hline $25-30$ & 32 & $20 \cdot 5$ & 9 & $5 \cdot 2$ & & 38 & $44 \cdot 2$ & 42 & $53 \cdot 2$ \\
\hline $30+$ & 2 & $1 \cdot 3$ & 2 & $1 \cdot 1$ & & 24 & $27 \cdot 9$ & 19 & $24 \cdot 1$ \\
\hline Income (€ gross/annual) & & & & & Income (€ net/month) & & & & \\
\hline 0-25000 (<modal $) \ddagger$ & 17 & $10 \cdot 9 \S$ & 35 & $20 \cdot 1$ & 0-1588 ( $\leq$ modal) & 33 & $37 \cdot 1$ & 16 & $20 \cdot 0$ \\
\hline $25000-50000$ ( $\geq$ modal $)$ & 30 & $19 \cdot 2$ & 31 & $17 \cdot 8$ & $1589+($ modal +$)$ & 56 & $62 \cdot 9$ & 64 & $80 \cdot 0$ \\
\hline $50000+($ modal ++$)$ & 109 & $69 \cdot 9$ & 108 & $62 \cdot 1$ & & & & & \\
\hline \multicolumn{10}{|l|}{ Education level } \\
\hline Low & 4 & $2 \cdot 5$ & 4 & $2 \cdot 3$ & & 18 & $19 \cdot 8$ & 14 & $17 \cdot 5$ \\
\hline Medium & 75 & $47 \cdot 8$ & 77 & $43 \cdot 8$ & & 55 & $60 \cdot 4$ & 44 & $55 \cdot 0$ \\
\hline High & 78 & $49 \cdot 7$ & 95 & $54 \cdot 0$ & & 18 & $19 \cdot 8$ & 22 & $27 \cdot 5$ \\
\hline
\end{tabular}

tIn $2007,40 \cdot 9 \%$ of men and $27 \cdot 7 \%$ of women in the general Dutch population were overweight $\left(\mathrm{BMI}=25-30 \mathrm{~kg} / \mathrm{m}^{2}\right)$, and $11 \cdot 2 \%$ of $\mathrm{men}$ and $10 \cdot 2 \%$ of women were obese $\left(\mathrm{BMI}>30 \mathrm{~kg} / \mathrm{m}^{2}\right)^{(30)}$.

$\ddagger$ The modal gross annual income in the Netherlands (in 2007) was $€ 30000^{(44)}$

§National statistics reveal that (in 2007) $52 \cdot 7 \%$ of Dutch households had an income above modal ${ }^{(35)}$. 
For LASA this included twenty-nine participants and for AGHLS forty participants. Then, we first analysed the association between energy density and energy costs in single food items using simple Pearson's correlations. Following that, we analysed this association on diet level using both simple Pearson's correlations and linear regression methods. Subsequently, participants were stratified into quartiles of consumed energy density and differences between the four groups were analysed with respect to diet costs per day, $\mathrm{kJ}$ per day, and fruit and vegetable intake, using one-way ANOVA. Finally, initial analyses were done to study differences between income levels regarding dietary energy density, fruit and vegetable intake, and diet costs, using ANOVA and Student's $t$ tests. Data for the AGHLS and LASA cohorts were analysed separately, and due to different energy requirements, data for men and women as well. Analyses were conducted using the SPSS statistical software package version 15.00 (SPSS Inc., Chicago, IL, USA).

\section{Results}

Table 1 shows participant characteristics for both the AGHLS and LASA populations. Both cohorts had a good dispersal of men and women, but differed on other parameters. Compared with the general Dutch population, we observed that overweight and obesity rates in the AGHLS population were lower (in AGHLS $20 \%$ of men were overweight and 1\% obese, compared with $40 \cdot 9 \%$ and $27 \cdot 7 \%$ in the general population) ${ }^{(30)}$. In LASA overweight and obesity rates were higher, at $44 \%$ and $28 \%$ for men, respectively. Analyses on fruit and vegetable consumption revealed that intake in the AGHLS population was higher compared with the LASA subjects; these numbers can also be considered high compared with the general population ${ }^{(1)}$.

\section{Association between energy density and costs in single food items}

First, we analysed the association between energy density and energy costs in single food items. Results are shown in Fig. 1. This figure displays, for twenty-two different food items, the energy density ( $y$-axis) relative to the energy costs ( $x$-axis). Because of the large range of values, data are plotted on a logarithmic scale. Results show that there exists a significant inverse relationship between energy costs and energy density in single food items $(r=-0 \cdot 436, P<0 \cdot 01)$. Food items with the highest energy density can be purchased for the lowest costs. For example, spinach costs $€ 5 \cdot 25 / 418 \mathrm{~kJ}$ (100 kcal) while peanut butter costs $€ 0 \cdot 035 / 418 \mathrm{~kJ}(100 \mathrm{kcal})$.

\section{Dietary energy density, fruit and vegetable intake, and diet costs}

Following the analyses on single food items we analysed the correlation between dietary energy density and diet costs, starting with Pearson's correlations. Results are

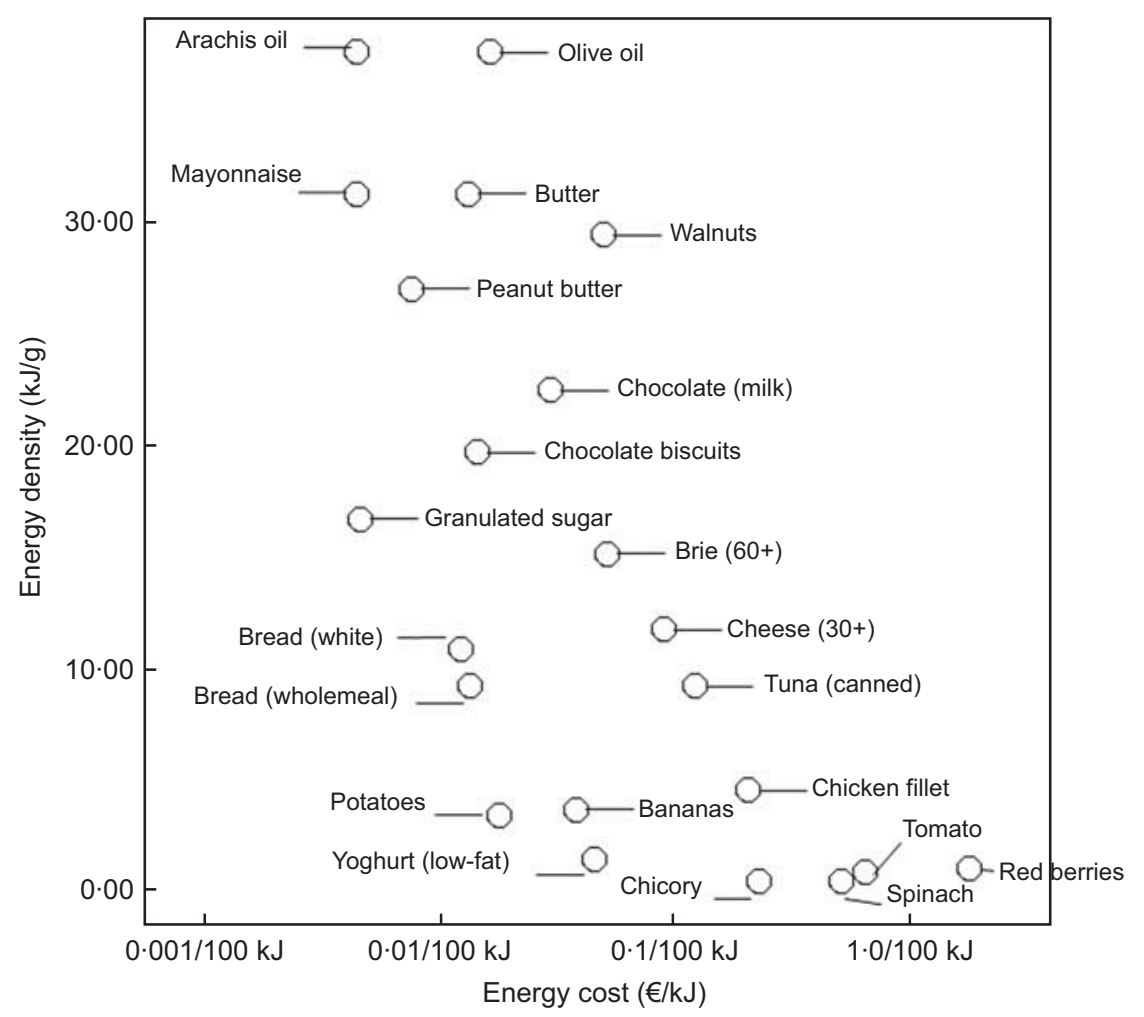

Fig. 1 Association between energy density $(\mathrm{kJ} / \mathrm{g})$ and energy costs $(€ / \mathrm{kJ})$ in single food items (logarithmic scale; $r=-0 \cdot 436$, $P<0.01$ ) for the studied populations: young adults from the Amsterdam Growth and Health Longitudinal Study (measured in 2000) and community-dwelling elderly from the Longitudinal Ageing Study Amsterdam (measured in 2007) 
(a)

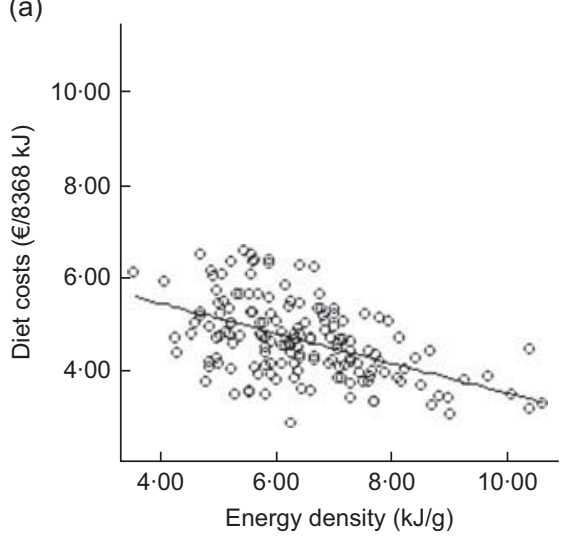

(c)

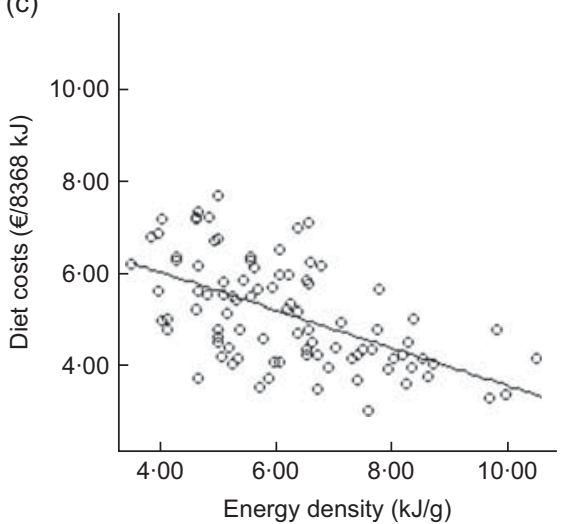

(b)

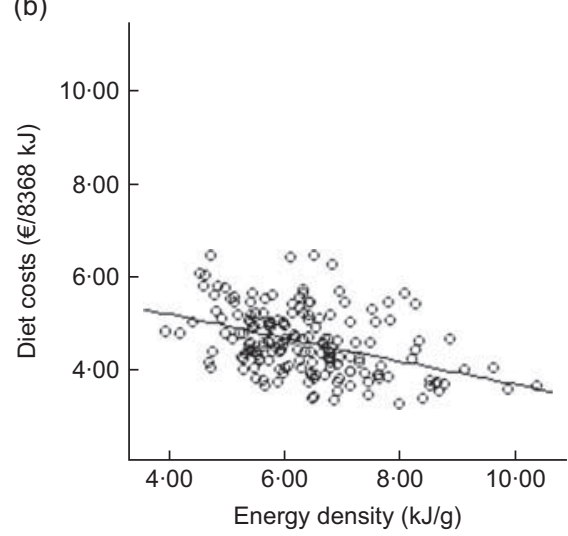

(d)

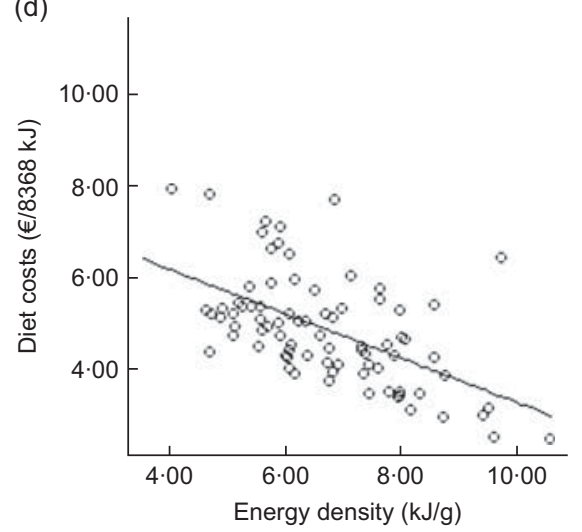

Fig. 2 Association between dietary energy density $(\mathrm{kJ} / \mathrm{g})$ and diet costs $(€ / 8368 \mathrm{~kJ}(2000 \mathrm{kcal}))$ for men and women of the studied populations, young adults from the Amsterdam Growth and Health Longitudinal Study (AGHLS, measured in 2000) and community-dwelling elderly from the Longitudinal Ageing Study Amsterdam (LASA, measured in 2007): (a) AGHLS men $(r=-0.505, P<0.001)$; (b) AGHLS women $(r=-0.413, P<0.001)$; (c) LASA men $(r=-0.559, P<0.001)$; (d) LASA women $(r=-0.562, P<0.001)$

shown in Fig. 2. The plots show a significant negative correlation between the two parameters in both cohorts, for both men and women. People consuming diets with a higher energy density had significantly lower diet costs (AGHLS men $r=-0 \cdot 505$, women $r=-0 \cdot 413, P<0 \cdot 001$; LASA men $r=-0.559$, women $r=-0.562, P<0.001$ ). Second, we analysed differences in energy intake per day, diet costs for $8368 \mathrm{~kJ}$ ( $2000 \mathrm{kcal})$, and fruit and vegetable intake by level of dietary energy density (Table 2). For this purpose participants were stratified into quartiles of energy density $(\mathrm{kJ} / \mathrm{g})$ and differences between the four groups were analysed using ANOVA. Results show that, except for vegetable intake in LASA women, there were significant differences between the energy density groups on all variables. As people were stratified in the higher energy density quartiles, total consumed energy per day increased, fruit and vegetable intake decreased, and diet costs per $8368 \mathrm{~kJ}$ ( $2000 \mathrm{kcal})$ decreased significantly.

Diet composition and diet costs in relation to income As well as examining the association between dietary energy density, fruit and vegetable intake, and diet costs, we did some initial analyses on differences by income level regarding these variables. For this purpose, we compared values of the listed variables for different income groups based on modal income classifications. As described in the Methods section, AGHLS subjects were classified into three income groups and LASA subjects into two. Results of the analyses are shown in Table 3. We could not find significant differences between the income groups regarding diet costs, dietary energy density, consumed energy or fruit intake. Women in the highest compared with the lowest income group spent more on food per day (in AGHLS $+7 \%$ and LASA $+10 \%$ ), but this was not significant. For vegetables we found that AGHLS men in the highest income group had a significantly lower intake than those in the lowest income group $(-56 \mathrm{~g}, P=0 \cdot 014)$.

\section{Discussion}

Results of our study are the first, outside France and the USA, confirming the suggested inverse associations between energy density and energy costs in single food items and composed diets. We found that also in 
Table 2 Daily energy intake, diet costs per $8368 \mathrm{~kJ}(2000 \mathrm{kcal})$, and daily fruit and vegetable consumption by quartile of energy densityt of the studied populations: young adults from the Amsterdam Growth and Health Longitudinal Study (AGHLS, measured in 2000) and community-dwelling elderly from the Longitudinal Ageing Study Amsterdam (LASA, measured in 2007)

\begin{tabular}{|c|c|c|c|c|c|c|c|c|c|}
\hline & \multicolumn{8}{|c|}{ LASA men } & \multirow[b]{3}{*}{$P$} \\
\hline & \multicolumn{2}{|c|}{$\begin{array}{c}\text { Q1 }(0-5 \cdot 05 \mathrm{~kJ} / \mathrm{g}) \\
(n 25)\end{array}$} & \multicolumn{2}{|c|}{$\begin{array}{c}\text { Q2 }(5 \cdot 06-6 \cdot 00 \mathrm{~kJ} / \mathrm{g}) \\
(n 20)\end{array}$} & \multicolumn{2}{|c|}{$\begin{array}{c}\text { Q3 }(6 \cdot 01-7 \cdot 17 \mathrm{~kJ} / \mathrm{g}) \\
(n 23)\end{array}$} & \multicolumn{2}{|c|}{ 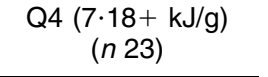 } & \\
\hline & Mean & SD & Mean & SD & Mean & SD & Mean & SD & \\
\hline Energy intake $(\mathrm{kJ} / \mathrm{d})$ & $4964 \cdot 3$ & $1470 \cdot 3$ & $5268 \cdot 9$ & $1578 \cdot 2$ & $\begin{array}{c}6060 \cdot 2 \\
5 \cdot 18\end{array}$ & $1355 \cdot 2$ & $6769 \cdot 7$ & $2137 \cdot 2$ & $\begin{array}{r}0.001^{* *} \\
-0.001^{* * *}\end{array}$ \\
\hline $\begin{array}{l}€ / 8368 \mathrm{~kJ}(2000 \mathrm{kcal}) \\
\text { Fruit }(\mathrm{g} / \mathrm{d})\end{array}$ & $\begin{array}{r}6 \cdot 01 \\
210 \cdot 7\end{array}$ & $\begin{array}{l}1 \cdot 08 \\
88.5\end{array}$ & $\begin{array}{r}5 \cdot 11 \\
156 \cdot 9\end{array}$ & $\begin{array}{r}0 \cdot 87 \\
116 \cdot 6\end{array}$ & $\begin{array}{c}5 \cdot 18 \\
118 \cdot 6\end{array}$ & $\begin{array}{c}1 \cdot 03 \\
91 \cdot 8\end{array}$ & $\begin{array}{c}4 \cdot 19 \\
81 \cdot 4\end{array}$ & $\begin{array}{l}0 \cdot 61 \\
69 \cdot 4\end{array}$ & $\begin{array}{l}<0.001^{\star \star \star} \\
<0.001^{\star \star \star}\end{array}$ \\
\hline Vegetables (g/d) & $169 \cdot 3$ & $74 \cdot 8$ & $155 \cdot 9$ & $92 \cdot 7$ & $120 \cdot 3$ & $66 \cdot 7$ & $100 \cdot 8$ & $70 \cdot 4$ & $0 \cdot 010^{*}$ \\
\hline
\end{tabular}

Energy intake $(\mathrm{kJ} / \mathrm{d})$ $€ / 8368 \mathrm{~kJ}(2000 \mathrm{kcal})$ Fruit $(\mathrm{g} / \mathrm{d})$ Vegetables $(\mathrm{g} / \mathrm{d})$
Energy intake $(\mathrm{kJ} / \mathrm{d})$ $€ / 8368 \mathrm{~kJ}(2000 \mathrm{kcal})$ Fruit $(\mathrm{g} / \mathrm{d})$ Vegetables $(\mathrm{g} / \mathrm{d})$

\begin{tabular}{|c|c|c|c|c|c|c|c|c|c|}
\hline & \multicolumn{8}{|c|}{ LASA women } & \\
\hline & \multicolumn{2}{|c|}{$\begin{array}{c}\text { Q1 }(0-5 \cdot 69 \mathrm{~kJ} / \mathrm{g}) \\
(n 20)\end{array}$} & \multicolumn{2}{|c|}{$\begin{array}{c}\text { Q2 }(5 \cdot 70-6 \cdot 59 \mathrm{~kJ} / \mathrm{g}) \\
(n 20)\end{array}$} & \multicolumn{2}{|c|}{$\begin{array}{c}\text { Q3 }(6 \cdot 60-7 \cdot 73 \mathrm{~kJ} / \mathrm{g}) \\
(n 20)\end{array}$} & \multicolumn{2}{|c|}{ 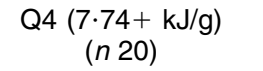 } & \\
\hline & Mean & SD & Mean & $\mathrm{SD}$ & Mean & $\mathrm{SD}$ & Mean & SD & \\
\hline Energy intake (kJ/d) & $5740 \cdot 0$ & $1200 \cdot 0$ & $6534 \cdot 6$ & $1848 \cdot 9$ & $6941 \cdot 7$ & $2201 \cdot 2$ & $7907 \cdot 8$ & $2160 \cdot 2$ & $0.006^{\star \star}$ \\
\hline$€ / 8368 \mathrm{~kJ}$ (2000 kcal) & $5 \cdot 61$ & $1 \cdot 04$ & $5 \cdot 23$ & 0.97 & $4 \cdot 76$ & 0.99 & 3.93 & $1 \cdot 03$ & $<0.001^{\star \star \star}$ \\
\hline Fruit $(\mathrm{g} / \mathrm{d})$ & $148 \cdot 9$ & $102 \cdot 7$ & $137 \cdot 6$ & $81 \cdot 3$ & $79 \cdot 7$ & $81 \cdot 9$ & $63 \cdot 8$ & $81 \cdot 0$ & $0.005^{\star \star}$ \\
\hline Vegetables (g/d) & $160 \cdot 1$ & $89 \cdot 6$ & $160 \cdot 1$ & $84 \cdot 3$ & $146 \cdot 5$ & $86 \cdot 2$ & $104 \cdot 8$ & $83 \cdot 7$ & $0 \cdot 145$ \\
\hline
\end{tabular}

LASA women

AGHLS men

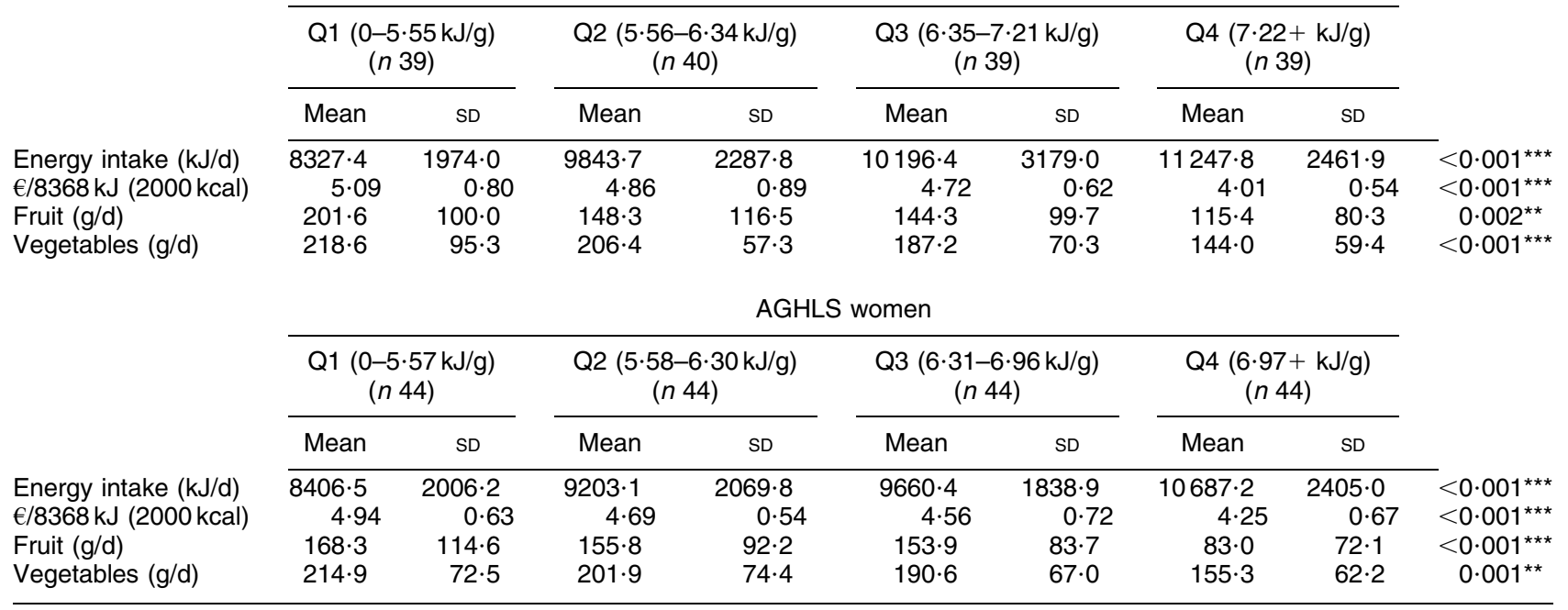

Significant difference between the four groups: ${ }^{*} P<0.05,{ }^{* *} P<0.01,{ }^{* \star *} P<0.001$.

tEnergy density $=$ amount of energy (kJ) per unit weight $(\mathrm{g})$.

The Netherlands it is cheaper to select energy-dense diets, instead of diets containing less energy. However, we could not find the expected differences in diet costs, dietary energy density, and fruit and vegetable intake by income level.

In the first part of our study we investigated the association between energy density and food costs in single food items; and the association between energy density, fruit and vegetable intake and costs in composed diets. In line with previous findings, our study revealed that energy costs for food items with a high energy density level were significantly lower compared with food items with a lower energy density ${ }^{(29)}$. When we further analysed the association on diet level, we found that diet costs and dietary energy density were inversely related as well. Again, these findings are in line with previous results $^{(12,28,29)}$. The fact that we could confirm previous findings using Dutch data has some important implications. Up until now, findings were restricted to American and French studies; with our study it has been shown that similar associations are present in another West European country with different cultural and dietary habits from the French $^{(17)}$. With this finding, there is reason to suggest that the association between energy density and energy costs also exists in other Western countries, which has important implications for obesity research. When healthier diets tend to cost more, economics may be of similar relevance in the onset of obesity as, for example, biological preferences for sugar and fat, growing portion sizes, caloric beverages, or the contribution of eating away from 
Table 3 Differences in daily energy intake, daily food expenses, energy density, diet costs per $8368 \mathrm{~kJ}$ ( $2000 \mathrm{kcal})$, daily fruit and vegetable consumption, and education by income level of the studied populations: young adults from the Amsterdam Growth and Health Longitudinal Study (AGHLS, measured in 2000) and community-dwelling elderly from the Longitudinal Ageing Study Amsterdam (LASA, measured in 2007)

\begin{tabular}{|c|c|c|c|c|c|c|c|c|c|c|c|c|c|c|}
\hline & \multicolumn{7}{|c|}{ AGHLS men } & \multicolumn{7}{|c|}{ AGHLS women } \\
\hline & \multicolumn{6}{|c|}{ Income groupt } & \multirow[b]{3}{*}{$P$ (ANOVA) } & \multicolumn{6}{|c|}{ Income group } & \multirow[b]{3}{*}{$P($ ANOVA $)$} \\
\hline & \multicolumn{2}{|c|}{$1(n 17)$} & \multicolumn{2}{|c|}{$2(n 30)$} & \multicolumn{2}{|c|}{$3(n$ 109) } & & \multicolumn{2}{|c|}{$1(n 35)$} & \multicolumn{2}{|c|}{$2(n 31)$} & \multicolumn{2}{|c|}{$3(n 108)$} & \\
\hline & Mean & SD & Mean & SD & Mean & SD & & Mean & SD & Mean & SD & Mean & SD & \\
\hline Energy intake $(\mathrm{kJ} / \mathrm{d})$ & $9908 \cdot 1$ & $1930 \cdot 9$ & $9637 \cdot 4$ & $2770 \cdot 2$ & $9995 \cdot 2$ & $2801 \cdot 6$ & $0 \cdot 815$ & $9432 \cdot 4$ & $2087 \cdot 4$ & $9439 \cdot 5$ & $2246 \cdot 0$ & $9520 \cdot 7$ & $2246 \cdot 0$ & 0.952 \\
\hline Food expenses $(€ / d)$ & $5 \cdot 89$ & $1 \cdot 26$ & $5 \cdot 13$ & $1 \cdot 17$ & $5 \cdot 38$ & $1 \cdot 30$ & $0 \cdot 146$ & $4 \cdot 88$ & 0.96 & $5 \cdot 16$ & $1 \cdot 22$ & $5 \cdot 21$ & $1 \cdot 04$ & $0 \cdot 261$ \\
\hline Energy density (kJ/g) & $6 \cdot 23$ & 0.92 & $6 \cdot 49$ & $1 \cdot 46$ & $6 \cdot 52$ & $1 \cdot 34$ & 0.678 & $6 \cdot 65$ & $1 \cdot 13$ & $6 \cdot 40$ & $1 \cdot 34$ & $6 \cdot 36$ & 1.09 & 0.410 \\
\hline$€ / 8368 \mathrm{~kJ}(2000 \mathrm{kcal})$ & 5.03 & 0.89 & $4 \cdot 60$ & $0 \cdot 84$ & $4 \cdot 62$ & 0.79 & $0 \cdot 142$ & $4 \cdot 40$ & 0.59 & $4 \cdot 65$ & $0 \cdot 76$ & $4 \cdot 66$ & 0.67 & $0 \cdot 126$ \\
\hline Fruit $(g / d)$ & $176 \cdot 5$ & $98 \cdot 4$ & $153 \cdot 2$ & $125 \cdot 9$ & $147 \cdot 7$ & $98 \cdot 6$ & 0.571 & $138 \cdot 0$ & $99 \cdot 5$ & $124 \cdot 4$ & $115 \cdot 5$ & $145 \cdot 4$ & $91 \cdot 9$ & 0.571 \\
\hline \multirow[t]{2}{*}{ Vegetables (g/d) } & $234 \cdot 2$ & $69 \cdot 4$ & $196 \cdot 2$ & $79 \cdot 0$ & $178 \cdot 5$ & $73 \cdot 1$ & $0 \cdot 014^{*}$ & $183 \cdot 8$ & $80 \cdot 4$ & $204 \cdot 0$ & $84 \cdot 4$ & $186 \cdot 4$ & $62 \cdot 6$ & 0.423 \\
\hline & $n$ & $\%$ & $n$ & $\%$ & $n$ & $\%$ & & $n$ & $\%$ & $n$ & $\%$ & $n$ & $\%$ & \\
\hline \multicolumn{15}{|l|}{ Education level } \\
\hline Low & - & - & 1 & $3 \cdot 3$ & 3 & $2 \cdot 8$ & $0 \cdot 121$ & 3 & $8 \cdot 6$ & 1 & $3 \cdot 2$ & - & - & $0.046^{\star}$ \\
\hline Medium & 13 & $76 \cdot 5$ & 15 & $50 \cdot 0$ & 46 & $42 \cdot 2$ & & 18 & $51 \cdot 4$ & 12 & $38 \cdot 7$ & 46 & $42 \cdot 6$ & \\
\hline \multirow[t]{5}{*}{ High } & 4 & $23 \cdot 5$ & 14 & $46 \cdot 7$ & 60 & $55 \cdot 0$ & & 14 & $40 \cdot 0$ & 18 & $58 \cdot 1$ & 62 & $57 \cdot 4$ & \\
\hline & \multicolumn{7}{|c|}{ LASA men } & \multicolumn{7}{|c|}{ LASA women } \\
\hline & \multicolumn{6}{|c|}{ Income group } & & \multicolumn{6}{|c|}{ Income group } & \\
\hline & \multicolumn{2}{|c|}{$1(n 33)$} & & & \multicolumn{2}{|c|}{$2(n 56)$} & & \multicolumn{2}{|c|}{$1(n 16)$} & & & \multicolumn{2}{|c|}{$2(n 64)$} & \\
\hline & Mean & SD & & & Mean & SD & $P(t$ test $)$ & Mean & SD & & & Mean & SD & $P(t$ test $)$ \\
\hline Energy intake (kJ/d) & $5857 \cdot 6$ & $1955 \cdot 6$ & & & $5717 \cdot 0$ & $1745 \cdot 6$ & 0.730 & $6094 \cdot 4$ & $2640 \cdot 5$ & & & $6953 \cdot 8$ & $1816 \cdot 7$ & $0 \cdot 128$ \\
\hline Food expenses $(€ / d)$ & $3 \cdot 46$ & $1 \cdot 14$ & & & $3 \cdot 48$ & $1 \cdot 11$ & 0.948 & $3 \cdot 61$ & $1 \cdot 64$ & & & 3.97 & $1 \cdot 22$ & 0.329 \\
\hline Energy density (kJ/g) & $5 \cdot 82$ & $4 \cdot 39$ & & & $6 \cdot 44$ & $1 \cdot 55$ & 0.069 & $6 \cdot 78$ & $1 \cdot 76$ & & & $6 \cdot 74$ & $1 \cdot 26$ & 0.835 \\
\hline$€ / 8368 \mathrm{~kJ}(2000 \mathrm{kcal})$ & $5 \cdot 03$ & $1 \cdot 05$ & & & $5 \cdot 20$ & $1 \cdot 19$ & 0.510 & $5 \cdot 05$ & $1 \cdot 62$ & & & $4 \cdot 84$ & $1 \cdot 04$ & 0.626 \\
\hline Fruit $(g / d)$ & 133.9 & $109 \cdot 5$ & & & $147 \cdot 7$ & $104 \cdot 0$ & 0.560 & $98 \cdot 2$ & $107 \cdot 2$ & & & $109 \cdot 8$ & $90 \cdot 0$ & 0.657 \\
\hline \multirow[t]{2}{*}{ Vegetables $(g / d)$} & $152 \cdot 4$ & $79 \cdot 4$ & & & $125 \cdot 9$ & $80 \cdot 4$ & $0 \cdot 139$ & $135 \cdot 4$ & $110 \cdot 0$ & & & $144 \cdot 7$ & $81 \cdot 4$ & $0 \cdot 704$ \\
\hline & $n$ & $\%$ & & & $n$ & $\%$ & & $n$ & $\%$ & & & $n$ & $\%$ & \\
\hline \multicolumn{15}{|l|}{ Education level } \\
\hline Low & 10 & $30 \cdot 3$ & & & 9 & $16 \cdot 1$ & $0.001^{\star *}$ & 8 & $50 \cdot 0$ & & & 6 & $9 \cdot 4$ & $<0.001^{\star * *}$ \\
\hline Medium & 22 & $66 \cdot 7$ & & & 31 & $55 \cdot 4$ & & 7 & $43 \cdot 8$ & & & 37 & $57 \cdot 8$ & \\
\hline High & 1 & $3 \cdot 0$ & & & 16 & $28 \cdot 5$ & & 1 & $6 \cdot 2$ & & & 21 & $32 \cdot 8$ & \\
\hline
\end{tabular}

Significant difference between the four groups: ${ }^{*} P<0.05,{ }^{* \star} P<0.01,{ }^{* \star *} P<0.001$

tIncome groups in AGHLS were measured in gross annual income, and are defined as $1=$ below modal, $2=$ around modal, $3=$ more than two times modal.

tlncome groups in LASA were measured in net monthly income, and are defined as $1=$ below modal, $2=$ above modal. 
home ${ }^{(29)}$. This economic argument comes on top of the fact that, in the current market-driven economy, fruits and vegetables may be less promoted than more lucrative highly processed foods ${ }^{(31)}$. In general, foods indicated as less favourable for health receive more marketing promotion than foods that are indicated to contribute to a healthy diet. Because of this skewed distribution of food prices and promotion, several authors argued that the introduction of pricing strategies may be a fair intervention to stimulate the selection of less fat- and sugar-rich food items ${ }^{(8,13,28,32,33)}$. Small-scale experiments on pricing strategies in controlled settings, such as schools and worksites, have revealed promising results regarding the effectiveness of such strategies ${ }^{(6,34)}$.

Because food pricing strategies may be particularly justifiable for low-income consumers, we conducted initial analyses to explore whether price is of additional importance in food selection for this subgroup. In this, we studied whether people with different income levels had different diet costs, dietary energy densities, and fruit and vegetable intakes. Unlike the suggested associations, we did not find significant differences. We did find some differences in diet costs per day and costs per $8368 \mathrm{~kJ}$ (2000 kcal) (e.g. AGHLS women in the highest income group spent $7 \%$ more on food per day than women with below-modal income, and in LASA this was even 10\%); however none of these results were significant. We expect this finding may be partly due to a power problem, because numbers, especially in the groups with belowmodal income, were small. Another point may be that we did not have data available on household composition. Numbers from Statistics Netherlands reveal that household size is an important contributor to disposable income, a factor we did not correct for ${ }^{(35)}$. Including disposable income, instead of annual income, may lead to the hypothesized differences by income level.

More importantly, we suggest that explanations can be found in the use of estimated diet costs in which sales, portion discounts, bundling discounts, or differences between expensive branded products and their low-cost equivalents, could not be taken into account. We made effort to correct for seasonal variability by collecting food prices of fruits and vegetables in a winter month (February) and a spring month (April) and including mean prices. Initial analyses on summer prices revealed that some products were cheaper (i.e. melon), but others were more expensive (i.e. apples), and mean prices were approximately the same. Still, we could not include the actual effect of seasonal variability on food choices, or how this differs among income groups. Low-income consumers may cut down expenses mainly by purchasing discounted food items, low-cost or seasonal foods ${ }^{(36)}$. We expect that the inclusion of discounts and other price differences between food products will reveal the expected differences in food expenditures between income groups. On top of this, food costs were exclusively based on solid foods, excluding beverages. Low-income shoppers may consume more soft drinks and sugarsweetened beverages, which are important contributors to energy density, and therefore differentiate between high- and low-income consumers ${ }^{(37)}$. A final point is that we did not take other food expenditures into account, such as eating out of home, which has also been found to be an important determinant in diet quality ${ }^{(38)}$.

Still, the chosen method is a regularly used and wellfounded way to estimate diet costs ${ }^{(26)}$. Our estimation on daily food expenses of on average $€ 5$ was similar to the mentioned French studies ${ }^{(12,26,29)}$. We suggest that the chosen method is well suited to study the relationship between energy density and energy costs, which is supported by our clear results on this aspect. However, to reveal differences by income level and to get insight into the actual effect of food prices on the consumer, other methods (recording exact food expenditures) may be required.

Apart from the above-described restrictions, it is important to note some concerns regarding the cohorts used. AGHLS and LASA are two different cohorts with clearly different characteristics and different dietary intake measures. We deliberately included both cohorts in order to be confident that the results found were not restricted to a selective cohort or specific measurement methods. This makes that the results of both cohorts are not directly comparable. Still, this can be considered a merit of our study since the results of both AGHLS and LASA point in the same direction. Also, both cohorts used standardized methods for measuring dietary intake and contain detailed, recent information of a relatively large sample. A limit of both cohorts is that they included only a small number of subjects with a low income. Because of this, the cut-off point for the income groups was set on modal income which is still quite high ( $€ 30000$ gross annually). Different results may be found when separate analyses are conducted on groups with a minimum income or below.

Furthermore, AGHLS and LASA had some unique limitations. First, the AGHLS cohort was fairly highly educated: even in the lowest-income group $24 \%$ of males and $40 \%$ of females were higher educated. Previous studies have shown that, next to income, education level is an important factor in food choice ${ }^{(39)}$. Moreover, AGHLS was a fairly healthy group. Both overweight and obesity numbers were low, and also the overall fruit and vegetable intake was high. Analyses on a lower educated, less healthy cohort may reveal other results. The LASA cohort was lower educated and less healthy, but may be biased because it includes exclusively an elderly population. Owing to changing taste and smell perceptions, and lower energy requirements, older subjects often have different eating patterns and a reduced energy intake compared with younger ones ${ }^{(40-42)}$. Because of these cohort limitations, the expected differences between 
income groups may have failed to appear. Also this may explain why our findings on fruit and vegetable intake were not evident. As differences in fruit and vegetable intake between SES groups are supported by a large body of evidence ${ }^{(2,43)}$, we expect that SES differences between our subjects were just too small to reveal such results.

Based on the outlined results we can conclude that also in The Netherlands it is cheaper to select a diet high in energy density and low in fruit and vegetables compared with a more nutrient-rich and less energy-dense diet. This complicates dietary advice aiming on the substitution of sugar- and fat-rich food items with fruits and vegetables, since it might result in higher diet costs. Still, we cannot conclude that this skewed price dispersal especially forms a barrier for low-income consumers. Initial analyses on this topic did not reveal clear differences in food intake and expenses between income groups. This may imply that financial barriers are not particularly prevalent among lowincome consumers; however we suggest that this finding may be more likely due to methodological limitations. Therefore, we suggest this topic should be more extensively studied in future research focusing on true food expenditures and including a good dispersal of SES groups. In this it is of importance to measure the exact type of food consumed (including brand), prices of these foods when purchased (including discounts), and also record foods that are consumed away from home. The availability of such data is of main importance to study the economics of obesity and healthy diets, and is needed in the aim of making the healthier choice the easy and affordable choice.

\section{Acknowledgements}

Sources of funding: This work was supported by a grant from the Netherlands Organisation for Health Research and Development (ZonMw; grant number 120510002). Conflicts of interest: None declared. Contribution(s) of each author: W.E.W. - conception and design, analysis and interpretation of data, drafting of the manuscript, statistical analysis; W.E.d.H. - conception and design, acquisition of data (prices and food composition), drafting of the manuscript, statistical analysis; I.v.A. - acquisition of data (prices and food composition); A.J.S. - critical revision of the manuscript; J.W.R.T. - acquisition of data (AGHLS); M.V. - acquisition of data (LASA); J.C.S. - critical revision of the manuscript, obtaining funding; I.H.M.S. - conception and design, interpretation of the data, critical revision of the manuscript, obtaining funding, supervision.

\section{References}

1. Busch MCM, Havelaar AH, Kramers PGN et al. (2004) Ons eten gemeten. Gezonde voeding en veilig voedsel in Nederland. Bilthoven: RIVM.
2. Giskes K, Turrell G, van Lenthe FJ et al. (2006) A multilevel study of socio-economic inequalities in food choice behaviour and dietary intake among the Dutch population: the GLOBE study. Public Health Nutr 9, 75-83.

3. Hulshof KF, Brussaard JH, Kruizinga AG et al. (2003) Socioeconomic status, dietary intake and 10 year trends: the Dutch National Food Consumption Survey. Eur J Clin Nutr 57, 128-137.

4. Lichtenstein DR, Ridgway NM \& Netemeyer RG (1993) Price perceptions and consumer shopping behavior: a field study. J Mark Res 30, 234-245.

5. Han S, Gupta S \& Lechmann DR (2001) Consumer price sensitivity and price thresholds. J Retail 77, 435-456

6. French SA (2003) Pricing effects on food choices. J Nutr 133, 841S-843S.

7. Cabanac M (1995) Palatability vs. money: experimental study of a conflict of motivations. Appetite 25, 43-49.

8. Cassady D, Jetter KM \& Culp J (2007) Is price a barrier to eating more fruit and vegetables for low-income families? J Am Diet Assoc 107, 1909-1915.

9. Glanz K, Basil M, Maibach E et al. (1998) Why Americans eat what they do: taste, nutrition, cost, convenience, and weight control concerns as influences on food consumption. J Am Diet Assoc 98, 1118-1126.

10. European Commission (2002) Risk Issues. Special Eurobarometer 238/Wave 64.1. Brussels: European Commission.

11. Drewnowski A (2004) Obesity and the food environment: dietary energy density and diet costs. Am J Prev Med 27, 3 Suppl., 154-162.

12. Darmon N, Briend A \& Drewnowski A (2004) Energy-dense diets are associated with lower diet costs: a community study of French adults. Public Health Nutr 7, 21-27.

13. Drewnowski A, Monsivais P, Maillot M et al. (2007) Lowenergy-density diets are associated with higher diet quality and higher diet costs in French adults. J Am Diet Assoc 107, 1028-1032.

14. Darmon N, Ferguson EL \& Briend A (2002) A cost constraint alone has adverse effects on food selection and nutrient density: an analysis of human diets by linear programming. J Nutr 132, 3764-3771

15. Maillot M, Darmon N, Vieux F et al. (2007) Low energy density and high nutritional quality are each associated with higher diet costs in French adults. Am J Clin Nutr 86, 690-696.

16. Naska A, Fouskakis D, Oikonomou E et al. (2006) Dietary patterns and their socio-demographic determinants in 10 European countries: data from the DAFNE databank. Eur J Clin Nutr 60, 181-190.

17. Slimani N, Fahey M, Welch AA et al. (2002) Diversity of dietary patterns observed in the European Prospective Investigation into Cancer and Nutrition (EPIC) project. Public Health Nutr 5, 1311-1328.

18. Darmon N \& Drewnowski A (2008) Does social class predict diet quality? Am J Clin Nutr 87, 1107-1117.

19. Bakker I, Twisk JW, van Mechelen W et al. (2003) Computerization of a dietary history interview in a running cohort; evaluation within the Amsterdam Growth and Health Longitudinal Study. Eur J Clin Nutr 57, 394-404.

20. Kemper HCG (1995) The Amsterdam Growth Study: A Longitudinal Analysis of Health, Fitness and Lifestyle. HK Sports Science Monograph Series, vol. 6. Champaign, IL: Human Kinetics Publishers Inc.

21. Kemper HCG (editor) (2004) Amsterdam Growth and Health Longitudinal Study: A 23-Year Follow-up from Teenager to Adult about Lifestyle and Health. Medicine and Sport Science Series, vol. 47 [J Borms, M Hebbelinck and AP Hills, editors]. Basel: Karger.

22. Deeg DJ, van Tilburg T, Smit JH et al. (2002) Attrition in the Longitudinal Aging Study Amsterdam. The effect of differential inclusion in side studies. J Clin Epidemiol 55, 319-328. 
23. Voedingscentrum (2006) NEVO tabel: Nederlands Voedingsstoffenbestand 2006/Stichting Nederlands Voedingsstoffenbestand (Dutch Food Composition Database). Den Haag: Voedingscentrum.

24. Ledikwe JH, Blanck HM, Khan LK et al. (2005) Dietary energy density determined by eight calculation methods in a nationally representative United States population. J Nutr 135, 273-278.

25. Albert Heijn Webwinkel (2007) Boodschappen. https:// webwinkel.ah.nl/ (accessed March 2008).

26. Monsivais P \& Drewnowski A (2007) The rising cost of lowenergy-density foods. J Am Diet Assoc 107, 2071-2076.

27. Born W (1987) Het complete kookboek. Weert: Uitgeverij M\&P.

28. Drewnowski A \& Darmon N (2005) Food choices and diet costs: an economic analysis. J Nutr 135, 900-904.

29. Drewnowski A, Darmon N \& Briend A (2004) Replacing fats and sweets with vegetables and fruits - a question of cost. Am J Public Health 94, 1555-1559.

30. Centraal Bureau voor de Statistiek (2009) Zelfgerapporteerde medische consumptie, gezondheid en leefstijl. http://statline.cbs.nl/StatWeb/publication/?DM=SLNL\&PA= $03799 \& \mathrm{D} 1=267-271 \& \mathrm{D} 2=0-17 \& \mathrm{D} 3=0 \& \mathrm{D} 4=\mathrm{a} \& \mathrm{VW}=\mathrm{T}$ (accessed February 2009).

31. Ludwig DS \& Nestle M (2008) Can the food industry play a constructive role in the obesity epidemic? JAMA 300, 1808-1811.

32. Andrieu E, Darmon N \& Drewnowski A (2006) Low-cost diets: more energy, fewer nutrients. Eur J Clin Nutr 60 , 434-436.

33. Ledikwe JH, Blanck HM, Khan LK et al. (2006) Low-energydensity diets are associated with high diet quality in adults in the United States. J Am Diet Assoc 106, 1172-1180.

34. French SA, Jeffery RW, Story M et al. (1997) A pricing strategy to promote low-fat snack choices through vending machines. Am J Public Health 87, 849-851.
35. Centraal Bureau voor de Statistiek (2009) Interactieve inkomensverdeling. http://www.cbs.nl/nl-NL/menu/themas/ inkomen-bestedingen/cijfers/extra/2008-inkomensverdeling. htm (accessed February 2009).

36. Darmon N, Caillavet F, Joly C et al. (2009) Low-cost foods: how do they compare with their brand name equivalents? A French study. Public Health Nutr 12, 808-815.

37. Vartanian LR, Schwartz MB \& Brownell KD (2007) Effects of soft drink consumption on nutrition and health: a systematic review and meta-analysis. Am J Public Health 97, 667-675.

38. Lin B-H, Guthrie J \& Frazão E (1999) Nutrient contribution of food away from home. In America's Eating Habits: Changes and Consequences, pp. 71-95 [E Frazão, editor]. Washington, DC: US Department of Agriculture.

39. Irala-Estevez JD, Groth M, Johansson L et al. (2000) A systematic review of socio-economic differences in food habits in Europe: consumption of fruit and vegetables. Eur J Clin Nutr 54, 706-714.

40. Wakimoto P \& Block G (2001) Dietary intake, dietary patterns, and changes with age: an epidemiological perspective. J Gerontol A Biol Sci Med Sci 56, Spec No 2, 65-80.

41. Drewnowski A \& Shultz JM (2001) Impact of aging on eating behaviors, food choices, nutrition, and health status. J Nutr Health Aging 5, 75-79.

42. Saini R \& Monga A (2008) How I decide depends on what I spend: use of heuristics is greater for time than for money. J Consum Res 34, 914-922.

43. Giskes K, van Lenthe F, Brug HJ et al. (2004) Dietary intakes of adults in the Netherlands by childhood and adulthood socioeconomic position. Eur J Clin Nutr 58, 871-880.

44. Wikipedia (2009) Modaal inkomen. http://nl.wikipedia.org/ wiki/Modaal_inkomen (accessed February 2009). 